\title{
Production performance and egg quality of quails (Coturnix japonica) during several periods of the day
}

\section{Author(s)}

Pizzolante CC

Faltarone ABG

Garcia EA

Saldanha ESPB

Deodato AP

Sherer MR

Mendes AA

Mori C

Pelicia K

FMZ - UNESP

Botucatu

Mail Address

Edivaldo Antonio Garcia

FMVZ-UNESP

Depto Produção Expl. ANimal

Caixa Postal 560

Distrito Rubião Jr

18.618-000. Botucatu, SP, Brasil

E-mail: egarcia@fca.unesp.br

\section{Keywords}

Periods of lay, egg production, lighting programs.

\section{ABSTRACT}

Three experiments were carried out to analyze the performance and egg quality of Japanese quails throughout the day when submitted to different lighting programs. In each experiment, birds were submitted to a period of 28 days for adaptation to the lighting program. During the following three days, each day - from 7 am to 7 pm or 9 pm - was divided into six or seven periods of two hours each, and the remaining hours corresponded to another single period. All birds were submitted to the same management practices, and received water and feed ad libitum. The experimental diet was formulated according to NRC (1994) standards. It was observed lower feed intake in the period of $9 \mathrm{pm}$ to $7 \mathrm{am}$, and a higher incidence of lay from 3 pm to 7 pm, as opposite to hens, which peak of egg laying occurs during the morning. Some controversial results were found among experiments as to eggshell quality during the different periods of the day. Variation on the lighting program had little influence on the other performance and egg quality parameters.

\section{INTRODUCTION}

The production of eggs with eggshell quality is an important concern of the egg industry. According to Roland (1988), losses due to low eggshell quality or other reasons may reach $20 \%$ before the eggs arrive at retail. Hurwitz (1989) asserted that the nutritional factors that affect eggshell quality depend on the metabolic exchanges, which occur during egg formation. In the uterus, the organic fraction of the eggshell is synthesized by the glands, and calcium - its largest component - is mobilized from the blood. Eggshell is sensitive to calcium availability, and carbonate is influenced by dietary factors that affect acid-base balance. This author also observes that eggshell mineral content is $90 \%$, out of which $98 \%$ consist of calcium carbonate. It is well known that, during eggshell formation, the transference of calcium from the plasma to the uterus in layers in very fast, of an average of one minute.

According to Etches (1996), eggshell is formed mostly during the night, when birds do not eat, and this may increase calcium deficiency for egg formation. Therefore, calcium is mobilized from the bones. Leeson et al. (1991) verified that calcium requirements are generally very low, except at the time eggshell is deposited. Faria et al. (2000) observed that commercial layers lay more frequently during the morning, after a period of fasting during the night, when eggshell is formed.

Aiming at improving eggshell quality in commercial layers, Joly (2003) mentions some techniques, such as feeding calcium-rich feeds in the afternoon, high particle size calcium dietary addition, short lighting period during the night, etc. However, in order to successfully apply these techniques in quails, feed intake behavior and lay times must be similar between these two bird species. 
Pizzolante CC, Faltarone ABG, Garcia EA, Saldanha ESPB, Deodato AP, Sherer MR, Mendes AA, Mori C, Pelicia K

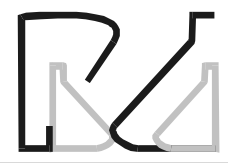

Production performance and egg quality of quails (Coturnix japonica) during several periods of the day
Therefore, this study aimed at investigating performance, internal egg quality, and eggshell quality parameters of quails during the day, and the possible influence of the lighting program on these parameters.

\section{MATERIAL AND METHODS}

Three experiments were carried out. The first two were carried out at the facilities of the Research and Development Unit of APTA Regional Centro Oeste. A total number of 400 female Japanese quails with 41 weeks of age at the beginning of the experiments were used. Birds were housed in a 15-m long and 4-m wide house, equipped with 60 wire quail cages, measuring $99 \mathrm{~cm} \times 330 \mathrm{~cm} \times 16 \mathrm{~cm}$ (length $\times$ width $\times$ height). Each cage, specific for egg production, had 4 compartments. Five birds were housed per compartment, with a total of 20 birds per cage. Each cage was equipped with a nipple drinker and a trough feeder.

A lighting program of 18 hours light and six hours dark was used for the first 28 days. In the first experiment, light was supplied from 7 am to $7 \mathrm{pm}$ and from $1 \mathrm{am}$ to $7 \mathrm{am}$, after which performance and egg quality data were collected for three consecutive days. During the three days of data collection, the period between $7 \mathrm{am}$ and 7 pm was divided into six periods of two hours each, whereas the remaining hours (7 pm to $7 \mathrm{am}$ ) corresponded to a single period, thereby characterizing seven treatments. A completely randomized experimental design was used, with seven treatments (times of data collection), and 20 replicates of 20 birds each.

The second experiment used the same facilities and equipment as the first experiment, and also a lighting program of 18 hours of light and six hours of dark for 28 days. However, light was supplied from 7 am to 1 am. Thereafter, during three consecutive days, the period between 7 am and 9 pm was divided into seven periods of two hours each, and the remaining hours (9 pm to $7 \mathrm{am}$ ) corresponded to a single period, characterizing eight treatments. A completely randomized experimental design was used, with eight treatments (times of data collection), and 20 replicates of 20 birds each, with a total of 400 birds.

The third experiment was carried out at the facilities of the poultry sector of the Egárdia Experimental Farm, belonging to the School of Veterinary Medicine and Animal Science - UNESP, Botucatu campus. A total number of 216 meat-type quails, during egg production stage, with 40 weeks of age at the beginning of the experiment, was used. Birds were housed in a 15-m long and 7-m wide poultry house, equipped with 144 wire cages (96-com long, 33-cm wide, 16-com tall) specific for egg production, with three compartments each. Eighteen cages were used. Each cage was equipped with nipple drinker and a trough feeder. Each compartment housed 4 birds, with a total of 12 birds per cage. In this experiment, a lighting program of 17 hours of light (4:00 am to 9:00 pm) and 7 hours of dark was applied. This program was maintained for 28 days, after which, the period between 7:00 am to 9:00 pm was divided into seven periods of 2 hours each, whereas the remaining hours (9:00 pm to 7:00 am) consisted of a single period, with a total of eight periods, for the next three days. A completely randomized experimental design, with eight treatments (data collection times) and 12 replicates of 12 birds, was applied.

Birds from all experiments were fed a single diet based on corn and soybean meal according to the NRC (1994) recommendations for laying quails in lay.

In all experiments, at the end of each 28-day period, the following traits were evaluated for three consecutive days: feed intake percentage per hour, percentage of lay per hour, mean egg weight, specific gravity, albumen percentage, yolk percentage, and eggshell percentage in each period. Data were analyzed using GLM (General Linear Models) procedure of SAS (SAS INSTITUTE, 1996) software, and means were compared using the test of Tukey at $5 \%$ de significance.

\section{RESULTS AND DISCUSSION}

Mean performance and egg quality results obtained during three consecutive days, after a 28-day adaptation period to the lighting program, relative to Experiment 1, are presented in Table 1.

There was no effect ( $p>0.05$ ) on the periods of the day on eggshell percentage.

The period of the day influenced $(p<0.01)$ feed intake per hour. Feed intake was lower during the night (7 pm to $7 \mathrm{am}$ ), and highest from 5 pm to $7 \mathrm{pm}$, with the period of $7 \mathrm{am}$ to $5 \mathrm{pm}$ presenting intermediate values.

Lay percentage per hour was significantly influenced by the effect of time of data collection, presenting low values from $7 \mathrm{pm}$ to $1 \mathrm{pm}$, and increasing thereafter, with maximum value between $5 \mathrm{pm}$ and $7 \mathrm{pm}$.

There was an effect $(p<0.01)$ of the time of the day on albumen percentage, yolk percentage, and egg 
Pizzolante CC, Faltarone ABG, Garcia EA, Saldanha ESPB, Deodato AP, Sherer MR, Mendes AA, Mori C, Pelicia K
Production performance and egg quality of quails (Coturnix japonica) during several periods of the day specific gravity, with higher yolk percentage and lower albumen percentage between $5 \mathrm{pm}$ and $7 \mathrm{pm}$, and the highest specific gravity in eggs laid between 9 am and $11 \mathrm{am}$.

Mean performance and egg quality results obtained during three consecutive days, after a 28-day adaptation period to the lighting program, relative to Experiment 2, are presented in Table 2.

Feed intake percentage was influenced $(p<0.01)$ by the periods of the day, with the highest values obtained between 7 am and $1 \mathrm{pm}$, and lowest values found during the night period.

Lay percentage was also affected $(p<0.01)$ by the periods of the day, with the lowest egg production from $9 \mathrm{pm}$ to $1 \mathrm{am}$, which increased thereafter, reaching maximum production in the period between $5 \mathrm{pm}$ and $7 \mathrm{pm}$, and then decreasing.
The periods of the day influenced $(p<0.01)$ eggshell percentage, with the worst observed from 9 am to $11 \mathrm{am}$.

Other egg quality traits were not influenced by treatments ( $p>0.05)$.

Mean performance and egg quality results obtained during three consecutive days, after a 28-day adaptation period to the lighting program, relative to Experiment 3, are presented in Table 3.

Times of the day did not affect ( $p>0.05$ ) egg weight, eggshell percentage, albumen percentage, yolk percentage, or specific gravity. There was a significant effect of treatments on feed intake percentage and lay percentage per hour, with the highest feed intake values observed between $3 \mathrm{pm}$ and $9 \mathrm{pm}$, and the lowest between $9 \mathrm{pm}$ and $7 \mathrm{am}$.

Percentage of lay per hour presented its lowest values between $9 \mathrm{pm}$ and $1 \mathrm{pm}$, increasing thereafter,

\begin{tabular}{|c|c|c|c|c|c|c|c|}
\hline Period(hours) & Feed intake* (\%) & Lay* (\%) & Egg weight (g) & Eggshell (\%) & Albumen(\%) & Yolk (\%) & Specific Gravity \\
\hline 7 pm - 7 am & $2.25^{d}$ & $1.53^{d}$ & 11.43 & 8.18 & $62.65^{\mathrm{ab}}$ & $29.17^{b}$ & $1.075^{\mathrm{ab}}$ \\
\hline $7 a m-9 a m$ & $6.67^{t}$ & $0.66^{d}$ & 11.14 & 7.44 & $64.47^{\mathrm{a}}$ & $28.09^{b}$ & $1.069^{c}$ \\
\hline $9 a m-11 a m$ & $5.79^{c}$ & 0.56 & 11.50 & 8.27 & $61.92^{a b}$ & $29.80^{\mathrm{ab}}$ & $1.079^{a}$ \\
\hline $11 \mathrm{am}-1 \mathrm{pm}$ & $5.68^{c}$ & $1.32^{d}$ & 11.01 & 7.94 & $61.45^{b}$ & $30.60^{a}$ & $1.074^{\mathrm{ab}}$ \\
\hline $1 p m-3 p m$ & $5.42^{c}$ & $6.30^{c}$ & 11.15 & 8.02 & $61.72^{b}$ & $30.26^{a b}$ & $1.074^{\mathrm{ab}}$ \\
\hline $3 p m-5 p m$ & $5.50^{c}$ & $14.06^{b}$ & 11.13 & 8.12 & $62.24^{\mathrm{ab}}$ & $29.64^{\mathrm{ab}}$ & $1.073^{b}$ \\
\hline $5 p m-7 p m$ & $7.45^{\mathrm{a}}$ & $17.92^{a}$ & 11.07 & 8.13 & $61.40^{b}$ & $30.47^{a}$ & $1.074^{\mathrm{ab}}$ \\
\hline CV $(\%)$ & 14.15 & 49.94 & 6.75 & 5.80 & 2.40 & 4.41 & 0.30 \\
\hline P & $<0.01$ & $<0.01$ & $>0.05$ & $>0.05$ & $<0.01$ & $<0.01$ & $<0.01$ \\
\hline
\end{tabular}

* Averages per hour in each period. Averages followed by different letters in the same column are significantly different by the test of Tukey (5\%).

\begin{tabular}{|c|c|c|c|c|c|c|c|}
\hline Period (hours) & Feed intake* $(\%)$ & Lay* $(\%)$ & Egg weight (g) & Eggshell (\%) & Albumen(\%) & Yolk (\%) & Specific Gravity \\
\hline $9 \mathrm{pm}-7 \mathrm{am}$ & $3.12^{d}$ & $0.35^{d}$ & 10.10 & $8.68 a$ & 63.69 & 27.63 & 1.068 \\
\hline $7 a m-9 a m$ & $5.42^{a}$ & $0.00^{d}$ & - & - & - & - & - \\
\hline $9 a m-11 a m$ & $5.51^{\mathrm{a}}$ & $0.098^{d}$ & 8.00 & $6.32 b$ & 62.63 & 31.05 & 1.070 \\
\hline $11 \mathrm{am}-1 \mathrm{pm}$ & $5.45^{a}$ & $0.59^{d}$ & 9.33 & $8.58 a$ & 63.47 & 27.96 & 1.083 \\
\hline 1 pm - 3 pm & $4.61^{b c}$ & $1.22^{b}$ & 10.11 & $8.22 a$ & 62.71 & 29.07 & 1.079 \\
\hline $3 p m-5 p m$ & $4.09^{c}$ & $14.36^{b}$ & 10.17 & $7.82 \mathrm{ab}$ & 62.60 & 29.59 & 1.076 \\
\hline $5 p m-7 p m$ & $4.44^{b c}$ & $25.61^{\mathrm{a}}$ & 10.00 & $8.20 a$ & 61.98 & 29.81 & 1.076 \\
\hline $7 p m-9 p m$ & $4.86^{\mathrm{ab}}$ & 6.36 & 10.08 & $8.20 \mathrm{a}$ & 62.34 & 29.46 & 1.076 \\
\hline C.V $(\%)$ & 14.00 & 58.08 & 8.99 & 6.41 & 3.13 & 6.85 & 3.57 \\
\hline P & $<0.01$ & $<0.01$ & $>0.05$ & $<0.01$ & $>0.05$ & $>0.05$ & $>0.05$ \\
\hline
\end{tabular}

* Averages per hour in each period. Averages followed by different letters in the same column are significantly different by the test of Tukey ( $5 \%$ ).

\begin{tabular}{|c|c|c|c|c|c|c|c|}
\hline Period (hours) & Feed intake* $(\%)$ & Lay*(\%) & Egg weight (g) & Eggshell (\%) & Albumen(\%) & Yolk (\%) & Specific Gravity \\
\hline 9 pm - 7 am & $2.78^{\circ}$ & $0.77^{e}$ & 13.27 & 8.25 & 61.90 & 29.85 & 1.076 \\
\hline $7 a m-9 a m$ & $4.05^{d}$ & $1.79^{e}$ & 14.10 & 8.68 & 61.17 & 30.15 & 1.077 \\
\hline $9 a m-11 a m$ & $4.96^{c}$ & $1.33^{\mathrm{e}}$ & 13.56 & 8.50 & 61.09 & 30.41 & 1.078 \\
\hline $11 \mathrm{am}-1 \mathrm{pm}$ & $5.08^{c}$ & $2.21^{\text {de }}$ & 13.60 & 8.51 & 60.90 & 30.58 & 1.077 \\
\hline $1 p m-3 p m$ & $3.96^{d}$ & $4.64^{d}$ & 13.24 & 8.56 & 61.51 & 29.93 & 1.078 \\
\hline $3 p m-5 p m$ & $6.89^{a}$ & $12.23^{b}$ & 13.13 & 8.45 & 61.22 & 30.33 & 1.078 \\
\hline $5 p m-7 p m$ & $5.94^{b}$ & $16.09^{3}$ & 13.01 & 8.44 & 62.00 & 29.56 & 1.078 \\
\hline $7 p m-9 p m$ & $6.31^{a b}$ & $7.88^{c}$ & 13.18 & 8.89 & 61.06 & 30.05 & 1.076 \\
\hline CV $(\%)$ & 21.70 & 66.76 & 9.07 & 9.60 & 4.56 & 9.15 & 4.37 \\
\hline$P$ & $<0.01$ & $<0.01$ & $>0.05$ & $>0.05$ & $>0.05$ & $>0.05$ & $>0.05$ \\
\hline
\end{tabular}

* Averages per hour in each period. Averages followed by different letters in the same column are significantly different by the test of Tukey ( $5 \%$ ). 
Pizzolante CC, Faltarone ABG, Garcia EA, Saldanha ESPB, Deodato AP, Sherer MR, Mendes AA, Mori C, Pelicia K

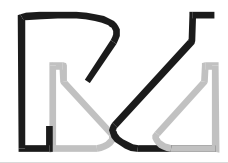

Production performance and egg quality of quails (Coturnix japonica) during several periods of the day and reaching a maximum value between $5 \mathrm{pm}$ and 7 pm.

Taking into account feed intake per hour for all three experiments, it was observed that, independent of light provision time, quails ate less during the night. This result is consistent with those of Maggioni (1996), who observed lower feed intake during the night in layertype chickens.

On the other hand, lay percentage per hour presented minimum values from $9 \mathrm{pm}$ and $1 \mathrm{pm}$, and its highest value between $5 \mathrm{pm}$ and $7 \mathrm{pm}$ in all three experiments, independent of the lighting program used. These results are different from Faria et al. (2000) e Joly (2003), who found that layer-type chickens had very high egg production during the morning.

Taking into account lay percentage in all three experiment, and correlating lay percentage to eggshell quality, experiment 2 presented the lowest eggshell percentage, and experiment 1, the highest specific gravity of eggs laid between 9 am and $11 \mathrm{am}$. These results are controversial, and not significant due to the low egg production observed at this time interval in all three experiments. On the other hand, after 3 pm, time of highest egg production in all three experiments, eggshell quality was also similar, independent of the lighting program. This shows that the lighting program had little or no influence on eggshell quality of eggs laid by quails during the periods of highest egg production. However, Joly (2003) asserted that eggs of layer-type chickens laid at the end of the morning present better quality, as seen by thicker eggshells.

Periods of the day and variations in the lighting program did not influence egg weight in none of the experiments.

\section{CONCLUSIONS}

Under the conditions of this research work, it is possible to conclude that, independent of the lighting program applied, there was lower feed intake during the night in all three experiments. Lay percentage per hour presented lowest values between $9 \mathrm{pm}$ and 1 $\mathrm{pm}$, and highest values between $5 \mathrm{pm}$ and $7 \mathrm{pm}$ in all experiments, independent of the lighting program. Egg weight was not influenced by time of the day in none of the experiments. The small variations in eggshell quality were not important as they occurred during periods of lowest lay percentage.

\section{REFERENCES}

Etches RJ. Reproduction in poultry. Cambridge: CAB International; 1996. p.318.

Faria DE, Junqueira OM, Sakomura NK, Santana AE. Sistemas de Alimentação e Suplementação de Farinha de Casca de Ostras Sobre o Desempenho e a Qualidade da Casca dos Ovos de Poedeiras Comerciais. Revista Brasileira Zootecnia 2000; 29(5):1394-1401.

Hurwitz S. Calcium homeostasis in birds. Vitamins and Hormones 1989; 45:173-221.

Joly P. Calidad de cáscara: importância de los horarios y de alumbrado. França: Hubbard Isa; 2003.

Leeson S, Summers J D. Commercial poultry nutrition. Guelph (CA): University Books; 1991.

Maggioni R, Rutz F, Roll VFB. Efeito do horário de fracionamento de dietas contendo diferentes níveis de cálcio sobre o desempenho produtivo e qualidade da casca em poedeiras semi pesadas no verão. In: Reunião Anual da Sociedade Brasileira de Zootecnia; 1996; Fortaleza, Ceará. Brasil. p.47-9.

National Research Council- NRC. Nutrient requirements of poultry. Washington(DC): National Academic Press; 1994. p.156.

Roland, DA. Eggshell problems: estimates of Incidence and economic impact. Poultry Science 1988; 67:1801-1803.

SAS Institute. SAS user's guide. Cary; 1996 